\title{
ESTIMATIONS OF THE WEIGHTED POWER MEAN BY THE HERON MEAN AND RELATED INEQUALITIES FOR DETERMINANTS AND TRACES
}

\section{MasATOSHI ITO}

Abstract. For positive real numbers $a$ and $b$, the weighted power mean $P_{t, q}(a, b)$ and the weighted Heron mean $K_{t, q}(a, b)$ are defined as follows: For $t \in[0,1]$ and $q \in \mathbb{R}, P_{t, q}(a, b)=$ $\left\{(1-t) a^{q}+t b^{q}\right\}^{\frac{1}{q}}$ and $K_{t, q}(a, b)=(1-q) a^{1-t} b^{t}+q\{(1-t) a+t b\}$. These means generalize the arithmetic and geometric ones.

In this paper, as a generalization of Wu and Debnath's result on non-weighted means (the case $t=\frac{1}{2}$ ), we get estimations of the weighted power mean by the weighted Heron mean. In other words, we obtain the greatest value $\alpha_{1}=\alpha_{1}(t, r)$ and the least value $\alpha_{2}=\alpha_{2}(t, r)$ such that the double inequality $K_{t, \alpha_{1}}(a, b)<P_{t, r}(a, b)<K_{t, \alpha_{2}}(a, b)$ holds for $t \in(0,1)$ and $r \in \mathbb{R}$. We can also obtain the results for bounded linear operators on a Hilbert space. Moreover, our main results lead some determinant and trace inequalities of matrices.

Mathematics subject classification (2010): 26E60, 15A45, 47A63.

Keywords and phrases: Power mean, Heron mean, operator mean, determinant inequality, trace inequality.

\section{REFERENCES}

[1] H. Alzer, C. M. Da Fonseca AND A. KovaČEC, Young-type inequalities and their matrix analogues, Linear Multilinear Algebra, 63 (2015), 622-635.

[2] R. A. Horn And C. R. Johnson, Topics in matrix analysis, Cambridge University Press, Cambridge, 1991.

[3] R. A. Horn And C. R. Johnson, Matrix analysis. 2nd ed., Cambridge University Press, Cambridge, 2013.

[4] M. ITO, Estimations of power difference mean by Heron mean, J. Math. Inequal., 11 (2017), 831-843.

[5] M. Iто, Estimations of the Lehmer mean by the Heron mean and their generalizations involving refined Heinz operator inequalities, Adv. Oper. Theory., 3 (2018), 763-780.

[6] W. JAnous, A note on generalized Heronian means, Math. Inequal. Appl., 4 (2001), 369-375.

[7] M. Khosravi, Some matrix inequalities for weighted power mean, Ann. Funct. Anal., 7 (2016), $348-357$.

[8] F. Kittaneh and Y. ManasRah, Improved Young and Heinz inequalities for matrices, J. Math. Anal. Appl., 361 (2010), 262-269.

[9] F. Kittaneh AND Y. ManasRah, Reverse Young and Heinz inequalities for matrices, Linear Multilinear Algebra, 59 (2011), 1031-1037.

[10] F. Kubo And T. Ando, Means of positive linear operators, Math. Ann., 246 (1980), 205-224.

[11] J. PeČArić, T. Furuta, J. MićIĆ Hot AND Y. SeO, Mond-Pečarić method in operator inequalities, Monographs in Inequalities 1, Element, Zagreb, 2005.

[12] S. Wu AND L. Debnath, Inequalities for differences of power means in two variables, Anal. Math., 37 (2011), 151-159.

[13] W.-F. XIA, S.-W. Hou, G.-D. WANG AND Y.-M. ChU, Optimal one-parameter mean bounds for the convex combination of arithmetic and geometric means, J. Appl. Anal., 18 (2012), 197-207. 